\title{
Aplicación Práctica de la Lógica en los Procesos Ad- ministrativos en Materia de Propiedad Intelectual
}

Practical Application of Logic in Administrative Processes in the Field of Intellectual Property

\author{
Luis Fernando Samaniego Izurieta \\ Investigador PUCE
}

Mgtr. Guillermo Gonzalo Lascano Báez

Profesor Titular PUCE (Facultad de Jurisprudencia)

Artículo Original (Revisión)

RFJ, No. 2, 2017, pp. 301-319, ISSN 2588-0837

RESUMEN: el documento, evalúa la aplicación de la lógica en los procesos administrativos en materia de propiedad intelectual. Adicionalmente establece los principales métodos para la utilización de la lógica en la propiedad intelectual y formula soluciones prácticas que abarquen los problemas asociados con la omisión de la lógica y los beneficios fruto de los mismos.

PALABRAS CLAVES: lógica jurídica, procesos administrativos, propiedad intelectual, principios, métodos.

ABSTRACT: the document evaluates the application of logic in administrative processes in the field of intellectual property. Additionally, it establishes the main methods for the use of logic in intellectual property and formulates practical solutions that encompass the problems associated with the omission of logic and the benefits derived from them.

KEY WORDS: legal logic, administrative processes, intellectual property, principles, methods. 


\section{INTRODUCCIÓN}

La propiedad intelectual es un factor socioeconómico que genera impacto a nivel individual y colectivo debido a la trascendencia e importancia que ha ganado en los últimos siglos. La propiedad intelectual está referida al régimen jurídico y los Derechos que se establecen sobre “(...) las creaciones de la mente: invenciones, obras literarias y artísticas, así como símbolos, nombres e imágenes utilizados en el comercio" ${ }^{197}$. Por ende, su protección opera como mecanismo para la promoción de desarrollo social puesto que el "progreso y el bienestar de la humanidad dependen de su capacidad de crear e inventar nuevas obras en las esferas de la tecnología y la cultura"198. En este contexto, es usual encontrar conflictos entre particulares, sobre signos distintivos, Derechos de autor u obtenciones vegetales, los cuales requieren la intervención y tutela estatal con el fin de garantizar la protección y cumplimiento de los Derechos legalmente reconocidos. Para este efecto, los distintos elementos de la lógica aplicables al Derecho, juegan un rol esencial en los procesos administrativos tutelados por el Estado. La optimización de los recursos disponibles, lenguaje empleado por los funcionarios públicos que tienen a su cargo la resolución de procesos administrativos, la correcta aplicación de las reglas de Derecho, la argumentación debidamente motivada, etc., son elementos de la lógica aplicables a la amplia gama de situaciones asociadas con la propiedad intelectual.

La falta de aplicación de la lógica en el ejercicio de las facultades estatales y la actuación de particulares conlleva a efectos perjudiciales, tanto para el Estado como para los particulares (quienes actúan en su calidad de administrados), pues producen falta, errónea o indebida motivación de las decisiones estatales. Mediante el monopolio de la coacción característica del Estado ${ }^{199}$, se establecen normas de conducta obligatorias que pueden encontrarse incorrectamente aplicadas, y que en el caso concreto de la propiedad intelectual puede conllevar a lesión de Derechos morales y patrimoniales para sus titulares. Como fue mencionado, la protección de la propiedad intelectual promueve el desarrollo en sus distintas ramas, sin embargo, las decisiones administrativas que no respondan a una aplicación lógica de la norma,

197 Organización Mundial de Propiedad Intelectual. ¿Qué es la Propiedad Intelectual?. 4.

198 Organización Mundial de Propiedad Intelectual. ¿Qué es la Propiedad Intelectual?. 3.

199 Trujillo Vásquez, J.C. (2006). Teoría del Estado en el Ecuador estudio de Derecho constitucional. 95. 
afectan sustancialmente la finalidad de la norma y por lo tanto desatienden el espíritu de “(...) establecer un equilibrio entre los intereses de los innovadores y el interés público, creando un entorno en el que la creatividad y la invención puedan florecer en beneficio de todos". ${ }^{200}$

El presente documento, evalúa la aplicación de la lógica en los procesos administrativos en materia de propiedad intelectual, y efectos adversos que provienen de su inobservancia. Adicionalmente se busca proyectar la realidad regional actual respecto a procesos bajo tutela estatal en materia de propiedad intelectual, establecer los principales métodos para la utilización de la lógica en la propiedad intelectual, formular soluciones prácticas que abarquen los problemas asociados con la omisión de la lógica y los beneficios fruto de los mismos.

\section{REALIDAD ACTUAL}

En Ecuador, se puede afirmar que la celeridad en la tramitación de los procedimientos es una de las mayores preocupaciones que atañen a la tutela judicial y administrativa efectiva. La sede administrativa con competencia en asuntos de propiedad intelectual en Ecuador es el Instituto Ecuatoriano de Propiedad Intelectual (en adelante IEPI), quien tiene a su cargo la tutela de Derechos de propiedad intelectual. Como sucede en toda rama del Derecho, en la cual la actividad argumentativa es un eje transversal, la lógica es una herramienta instrumental indispensable, en la sede administrativa.

El lenguaje, es el medio de comunicación de la raza humana, cuyo uso es imprescindible para cualquier actividad administrativa o judicial. La complejidad y excesivo tecnicismo que aporta el Derecho para los sujetos agentes como los principales, puede, ciertamente, dificultar la transmisión de ideas, conceptos, etc. Se podría decir que el lenguaje es "el instrumento y el vehículo con el cual nuestra mente distingue los elementos de la realidad, se mueve en ella, la comprende y comunica" ${ }^{201}$, pero un intrincado u obsoleto uso de lenguaje jurídico podría dificultar el entendimiento entre sujetos agentes e individuales.

La ineficiencia del sistema jurídico en los ámbitos de propiedad intelectual, deviene en el incremento de procesos administrativos. Me-

200 Organización Mundial de Propiedad Intelectual. ¿Qué es la Propiedad Intelectual?. 3

201 García Restrepo, L.E. (2011). Elementos de lógica para el Derecho. 1. 
diante los distintos recursos de impugnación legalmente establecidos, los agentes principales se ven obligados a reconocer costos adicionales debido a las múltiples instancias disponibles al público, lo cual pone en riesgo los intereses de las partes involucradas y como ya se mencionó, desmotiva la formalización de la propiedad intelectual.

Un ejemplo que sirve para evidenciar lo mencionado es la oposición de signos distintivos, en los casos donde los intereses de un titular de Derechos de propiedad intelectual ya existentes, se vean amenazados debido a la identidad e inclusive similitud entre el signo ya registrado y aquellos posteriormente solicitados. La Decisión 486 de la Comunidad Andina de Naciones, en su artículo 146 plantea que "dentro del plazo de treinta días siguientes a la fecha de la publicación, quien tenga legítimo interés, podrá presentar, por una sola vez, oposición fundamentada que pueda desvirtuar el registro de la marca" ${ }^{202}$. En este contexto, la lógica juega un papel fundamental al dotar de herramientas para la adecuada motivación de las resoluciones administrativas.

En conclusión, la propiedad intelectual juega un rol sustancial en la sociedad actual. Los Estados, alrededor del mundo juntan esfuerzos con el objetivo de promover la importancia de la propiedad intelectual, en sus distintos niveles, debido a la amplia gama de beneficios frutos de esta materia de Derecho. Sin embargo, enfrenta una serie de adversidades que deben ser superadas mediante la implementación de medidas que involucren el uso de la lógica. Se puede evidenciar, al igual que la mayoría de sedes administrativas y judiciales estatales, ineficiencia en los procesos y métodos adoptados para alcanzar los fines específicos de las instituciones. La comunicación es un elemento imprescindible para alcanzar cualquier meta, sin embargo, el uso de terminología incomprensible para los individuos ajenos al estudio del Derecho, imposibilita en muchos casos la igualdad de condiciones y consecuentemente se producen graves injusticias.

\section{MÉTODOS PARA LA APLICACIÓN DE LA LÓGICA}

La propiedad intelectual se divide conceptualmente en tres categorías principales: la propiedad industrial, los Derechos de autor y las obtenciones vegetales. En primer término, la propiedad industrial “(...) abarca las patentes de invención, las marcas, los diseños industria-

202 Comunidad Andina de Naciones, Lima-Perú. (2000). Decisión 486. 36. 
les y las indicaciones geográficas" ${ }^{203}$, y suele tener una mayor influencia comercial en los consumidores y el desarrollo social. Luego, se puede encontrar a los Derechos de autor que están destinados a la protección de las creaciones artísticas, entre los cuales abarcan:

“(...) las obras literarias (por ejemplo, las novelas, los poemas y las obras de teatro), las películas, la música, las obras artísticas (por ejemplo, dibujos, pinturas, fotografías y esculturas) y los diseños arquitectónicos. Los Derechos conexos al Derecho de autor son los Derechos de los artistas intérpretes y ejecutantes sobre sus interpretaciones o ejecuciones, los de los productores de fonogramas sobre sus grabaciones y los de los organismos de radiodifusión respecto de sus programas de radio y televisión” ${ }^{204}$

En este sentido, las oposiciones al registro que mediante la publicación en la gaceta de propiedad intelectual correspondiente, "tiene por objeto permitir a las personas enterarse de qué es lo que se está intentando proteger a través de la solicitud y les permite presentar oposiciones que intentan desvirtuar la posibilidad que la solicitud" ${ }^{205}$, ya sea de una patente o marca, no obtenga el registro que se pretendía. Es en este proceso administrativo, donde los sujetos principales y agentes, deben emplear un lenguaje que cumpla con "(...) cinco cualidades necesarias: sencillez, claridad, concisión, precisión y originalidad" ${ }^{206}$, con el fin de alcanzar una mejor transmisión de ideas y conceptos, que permitan a las partes alcanzar sus intereses individuales.

De esta forma, se asegura el ejercicio de la argumentación. De cumplir con estas cualidades, los sujetos agentes, se verían obligados a resolver a base de la argumentación expuesta por los distintos sujetos principales involucrados. La argumentación consiste en la "(...) justificación destinada a persuadir a un auditorio (persona o grupo) para que acepte una tesis (una idea, acción decisión, acusación, defensa, etc.) llevando mentes ajenas de un Estado a otro con respecto a la tesis, y es pertinente cuando esta no es inmediatamente aceptable, «no salta a la vista», o no se dispone de una demostración rigurosa o de una prueba indiscutible”207. En el caso de la propiedad intelectual, dicha justificación se fundamen-

203 Organización Mundial de Propiedad Intelectual. ¿Qué es la Propiedad Intelectual?. 4.

204 Organización Mundial de Propiedad Intelectual. ¿Qué es la Propiedad Intelectual?. 4.

205 Superintendencia de Industria y Comercio, Bogotá, Colombia. ABC De Propiedad Industrial. 20.

206 Lastra Lastra, J.M. (2003). Derecho a la lengua y lenguaje jurídico. 14.

207 García Restrepo, L.E. (2011). Elementos de lógica para el Derecho. 158. 
taría en las fuentes de Derecho conocidas como ley, jurisprudencia y doctrina, que deberán cumplir con las siguientes características:

“a) lógica: ningún hablante puede contradecirse; b) sinceridad: todo hablante puede afirmar solo lo que el mismo cree; c) coherencia: todo hablante que aplique una propiedad $P$ a un caso $C$, debe estar dispuesto a aplicar $P$ cualquier caso $N$ que sea igual a $C$ en todos los aspectos relevantes; precisión conceptual: los hablantes durante un proceso de comunicación no pueden usar la misma expresión con distintos significados”. ${ }^{208}$

Además, una adversidad que enfrentan todos los sujetos, tanto agentes como principales, es el persistente uso de falacias. Las falacias son "recursos argumentativos inaceptables desde el punto de vista racional pero psicológicamente persuasivos" ${ }^{209}$. Sin embargo, por más que sean consideradas inadmisibles, constantemente pasan desapercibidas, ya sea con la intención de engañar a las partes involucradas o un simple error al momento de elaborar un argumento. No obstante, de ser estas consideradas por los sujetos agentes, o al pasar desapercibidas en análisis de la parte opositora, puede resultar sumamente perjudicial en el momento que se emita un fallo oficial, puesto a que se pudiesen estar cometiendo graves injusticias producidas por simples mecanismos de engaño.

En segundo lugar, la propiedad intelectual se encuentra dividida en dos categorías conocidas como la propiedad industrial y los Derechos de autor. Dentro de la clasificación de la propiedad industrial, los Estados, tutelan un proceso denominado oposiciones al registro, donde posiblemente se encuentren las mayores injusticias y perjuicios producidos por la ausencia de la lógica en la praxis del Derecho. Dentro de esta práctica, tanto los sujetos agentes como principales, deben ser capaces de emplear las herramientas como el lenguaje, la identificación de falacias, o la argumentación apropiada, con el fin de obtener un fallo favorable y los más justo posible. Para que esto sea posible, el Derecho debe omitir la concepción que se tiene de una ciencia, puesto a que esta creencia induce a resistencia al cambio en una profesión social que se fundamenta en las realidades cambiantes de los entornos en los que habitan los individuos.

208 García Restrepo, L.E. (2011). Elementos de lógica para el Derecho. 158.

209 García Restrepo, L.E. (2011). Elementos de lógica para el Derecho. 167. 


\section{Soluciones prácticas}

Para el caso de las oposiciones a signos distintivos son aplicables una serie de principios, tanto para defender los intereses del solicitante como del opositor (titular previo de Derechos que ha sido capaz de demostrar legítimo interés). Al momento de solicitar el registro de un signo distintivo, ya sea signo marcario de fábrica, servicios, lemas o nombres comerciales, se debe especificar la Clase Internacional NIZA ${ }^{210}$ a la cual el signo distintivo se encuentra destinado a proteger. La protección de un signo distintivo únicamente recaerá sobre la Clase Internacional NIZA detallada y productos específicos de la misma. Es aquí donde entra la aplicación de la lógica, puesto a que los agentes principales deberán detallar de la mejor forma posible los productos o servicios protegidos, caso contrario, el signo solicitado podría entrar en conflicto con marcas previamente registradas y consecuentemente en las prohibiciones absolutas de registro legalmente establecidas, por lo que se deberá emplear un lenguaje lo más técnico y específico posible con el fin de obtener una decisión favorable en el caso de una oposición.

De cumplirse con las especificaciones antes mencionadas respecto a la protección de signo distintivo solicitado, las posibilidades que los intereses del solicitante sean cumplidos, incrementa sustancialmente. Aquí es donde entra el principio marcario denominado como "especialidad". En este sentido, "el hecho que el registro de una marca se conceda solo con respecto a una determinada clase, determina que una persona titular de un registro de marca no pueda evitar que un tercero registre una marca similar o idéntica en otras clases" ${ }^{211}$. Es por esto que los funcionarios administrativos deben ser muy minuciosos al momento de analizar los argumentos expuestos por las partes, puesto a que deberán ser capaces con las herramientas a su disponibilidad, de identificar cualquier tipo de relación o identidad entre los productos o servicios que pudieran culminar en efectos como la confusión o asociación. Sin embargo, la parte opositora, podría hacer uso del principio denominado de "vinculación" que consiste en una excepción al principio de especialidad y es aplicable en los casos donde "(...) dos productos o servicios presentan vinculación por su naturaleza o por la

210 Clase Internacional Niza.- "La Clasificación de Niza, establecida por el Arreglo de Niza (1957), es una clasificación internacional de productos y servicios que se aplica para el registro de marcas. La undécima edición entró en vigor el 1 de enero de 2017"

211 Área Derecho a la Competencia y Propiedad Intelectual, Actualidad Empresarial. (2009). Los principios aplicables a la protección de marcas. 4. 
forma como se comercializan, entonces, a pesar de estar en distintas clases, el titular del registro de una marca podría oponerse a que otra persona registre una marca idéntica en una clase de productos o servicios vinculados". Es por esto, que como ya se ha mencionado, el criterio del sujeto agente es sumamente importante puesto a que mediante su criterio personal debe ser capaz de identificar cualquier relación competitiva entre los signos en conflicto. Sin embargo, en gran parte de los casos, los sujetos agentes desarrollan mecanismos resolutivos repetitivos, donde omiten el análisis de los fundamentos y elementos de fondo de cada caso.

Al encontrarse más de una parte involucrada, al igual que en todo proceso administrativo o judicial, es aplicable el principio lógico de no contradicción en el que se deben fundamentar todos los sujetos agentes. Este principio, aplicable a la mayoría de los casos, consiste en "«dos juicios, de los cuales uno afirma lo que el otro niega, no pueden ser simultáneamente verdaderos» (...) «dos juicios contradictorios no pueden ser verdaderos ambos. De la definición del principio aludido se infiere que solamente uno de los dos juicios es falso". Es por esto que los sujetos agentes encargados de evaluar los argumentos expuestos por las partes, deben ser capaces de discernir el contenido manifEstado, con el fin de determinar cuál de las realidades es la correcta a través de la interpretación de las fuentes de Derecho vigentes.

Por todo lo mencionado es que se afirma que una educación legal práctica, fundamentada en técnicas y principios útiles resulta imprescindible tanto para aspirantes a profesionales en materia de Derecho, como cualquier operador administrativo o judicial en ejercicio activo de sus competencias. La implementación de cursos, que toleren, acepten y reciban nuevos pensamientos fundamentados en el aprendizaje y ejecución de los distintos tipos de lógica que permita a los estudiantes acoplar "(...) un pensamiento jurídico racional, fundamentado en las reglas de razonamiento y de la argumentación lógica" ${ }^{12}$ a su formación académica y ejercicio de labores profesionales. Como ya se mencionó previamente, las falacias pueden resultar seriamente perjudiciales, por lo que la identificación de las mismas y la impugnación de argumentos inválidos, deben sustituir a los cursos y prácticas obsoletas con el fin de optimizar los costos transaccionales y el acceso a la justicia en

212 Rosales Gramajo, F. (2010). Lógica Jurídica: Instrumento indispensable para el juez y el abogado litigante. 15. 
sus distintas materias, sobre todo respecto a la propiedad intelectual, cuyo campo de aplicación es cada vez más amplio e influyente.

"La oposición de juicios universales, en el que uno afirma lo que el otro niega, se llama contraria. Esta conclusión se deriva del siguiente extracto: «... si de una cosa universal se enuncia de una manera universal que es o que no es, las enunciaciones serán contrarias...». Actualmente esta oposición contradictoria entre juicios se designa con el mismo término." ${ }^{123}$ Por lo general, en oposiciones a los registros, se darán "oposiciones contradictorias" entre argumentos y posturas expuestas, por lo que el sujeto agente deberá evaluar aquella que considere como válida. De otro lado, en el legítimo Derecho a la réplica, las partes involucradas podrán impugnar los argumentos expuestos mediante una contestación debidamente motivada e interpuesta dentro de los términos legalmente establecidos. En este sentido, "un argumento ajeno se puede refutar cuando se demuestre que la conclusión es errónea, falsa, inconveniente, o jurídicamente insostenible; confutar o impugnarlo de modo conveniente, $u$ objetar cuestionando la evidencia, los valores, las doctrinas presentadas en favor de la conclusión" ${ }^{14}$.

Entre estrategias o métodos para la impugnación de argumentos aplicables en toda rama del Derecho, se desprenden los siguientes:

"1 Prolongar los argumentos o analogías del oponente a favor de nuestros argumentos.

2 Elogiar su talento, su prestigio, antes de «soltar» nuestros más poderosos argumentos.

3 Reclamarle pruebas o razones adicionales que sustenten sus premisas $y$ conclusiones.

4 Descubrir falacias formales (afirmación del consecuente, negación del antecedente, por ejemplo) que invaliden formalmente su discurso. $O$ señalar las falacias informales que comete (generalización apresurada, conclusión inatenta, causa falsa, círculo vicioso, etc.) (...)

5 Demostrar que los hechos argüidos como evidencia no están suficientemente bien establecidos.

213 Maynes García. Introducción a la Lógica Jurídica. 31.

214 García Restrepo, L.E. (2011). Elementos de lógica para el Derecho. 163. 
6 Objetar las presuposiciones o creencias básicas en que se fundamentan las premisas presentadas.

7 Cuando dé lugar, encontrar contradicciones, inconsistencias o incoherencias (como las que se escuchan en los discursos preelectorales cuando prometen extender y mejorar los servicios públicos sin elevar los impuestos ni la inflación).

8 Señalar posiciones anteriores del oponente que contradigan las actuales. Aúnque toda persona puede cambiar sus criterios con el tiempo, este recurso es retóricamente importante por cuanto presiona al oponente a presentar aclaraciones que terminan debilitando su nueva posición.

9 Destacar la irrelevancia o escasa importancia de los hechos o afirmaciones.

10 Hacerle o extinguirles distinciones, aclaraciones o precisiones a sus conceptos o a sus tesis claves.

11 Encontrar absurdos, es decir, demostrar que si se aceptan los puntos de vista del oponente se entra en franca contradicción con hechos, creencias o valores bien establecidos o aceptados por la mayoría.

12 Mostrar iguales consecuencias, es decir, hacer que el oponente tenga que admitir las mismas conclusiones que rechaza (...).

13 Contra-argumentar, o sea, usando las mismas premisas del adversario, llegar a una conclusión diferente.

14 Cuestionar la verosimilitud o el crédito de las proposiciones a partir de las cuales se argumenta (observaciones, testimonios, fuentes de información, etc.).

15 Emplear, con la mayor discreción, el recurso al chiste o a la ironía en el momento y auditorio apropiado (no todo el mundo es sensible a los gracejos).

16 Poner al descubierto problemas de percepción, reconocimiento, interpretación e inferencia en la argumentación del oponente." ${ }^{215}$

215 García Restrepo, L.E. (2011). Elementos de lógica para el Derecho. 163-164. 
En procesos de oposición al registro de un signo distintivo, el elemento de mayor influencia resolutiva es conocido como "distintividad". Este elemento tan importante es conocido usualmente como:

“(...) una característica, función y requisito de registro de las marcas comerciales. Se trata de un concepto flexible y dinámico en el tiempo, que varía de acuerdo al uso que se le dé al signo marcario. Así, la forma de cómo se usa el signo condiciona su distintividad, sea para obtenerla, aumentarla o incluso para perderla, lo cual a su vez puede incidir en el registro marcario." ${ }^{210}$

En este sentido, se puede determinar que es una característica indispensable que todo signo que pretenda ser registrado, debe poseer. Los sujetos agentes, deben ser capaces de determinar si los signos, que día a día son solicitados en un gran volumen, cumplen con esta cualidad. Usualmente, el método más empleado es el cotejo marcario que consiste en la evaluación de las similitudes entre los signos en conflicto sucesivamente, este proceso debe seguir las siguientes reglas:

"Regla 1. La confusión resulta de la impresión de conjunto despertada por las marcas.

Regla 2. Las marcas deben examinarse sucesivamente y no simultáneamente.

Regla 3. Deben tenerse en cuenta las semejanzas y no las diferencias que existen entre las marcas.

Regla 4. Quien aprecie el parecido debe colocarse en el lugar del comprador presunto y tener en cuenta la naturaleza de los productos. ${ }^{217}$

Este es un gran ejemplo, donde los operadores de justicia deberán regirse por reglas de conducta previamente establecidas. Sin embargo,

216 Schmitz Vaccaro, C. (2012). Distintividad y uso de las marcas comerciales. Revista Chilena de Derecho, vol. 39.

217 Tribunal de Justicia de la Comunidad Andina. (2016). Cotejo Marcario - Entre el signo CALMODOX y la marca CALMIDOL / Marcas Farmacéuticas - Rigurosidad de examen de confundibilidad / Expresión De Uso Común - Partícula CALM / Registro Marcario - Procedencia frente al signo CALMODOX al no existir semejanzas con la marca CALMIDOL. 13. 
la decisión final respecto a la factibilidad del registro depende de la valoración individual del funcionario encargado.

Finalmente, el último de los principios que se tratará en el presente documento, aplicable en la defensa de los intereses de las partes involucradas, específicamente en materia de propiedad intelectual, es el principio de coexistencia marcaria. Una marca, puede coexistir pacíficamente con otra, inclusive si es idéntica a otra ya registrada en la misma Clase Internacional Niza. Es por esto, que esto puede ser utilizado como argumento en la defensa de los intereses del solicitante de una marca. La pregunta que se tiene que formular a la autoridad competente es ¿Por qué si la marca opositora, pudo coexistir con otra proveniente a la misma Clase Internacional Niza, ya existente y cuyas características se asemejan, no podría coexistir con el signo recientemente solicitado? En este sentido, los sujetos agentes encargados de resolver sobre ese asunto específico, se encuentran obligados a evaluar la morfología conceptual de las marcas ya registradas, con el objeto de determinar la coexistencia marcaria. De comprobarse este argumento, el solicitante de la marca incrementaría sustancialmente su posibilidad de acceder a registro, sin embargo, existen métodos alternos para la resolución de este tipo de conflicto, denominados Acuerdos de Coexistencia Marcaria. Mediante dichos acuerdos, las partes involucradas pactan términos específicos que por lo general resultan en el desistimiento de la oposición a cambio de la limitación de los productos o servicios destinados a proteger por el signo distintivo solicitado. Para que esto se dé, se emplea como medio de comunicación el lenguaje, puesto a que, la parte solicitante deberá renunciar a la protección de los productos y servicios protegidos que puedan ser un riesgo competitivo para la parte opositora, por lo que deberá detallar lo más específicamente posible la protección marcaria mediante un lenguaje claro y conciso. Los acuerdos de coexistencia son definidos como:

“(...) aquellos pactos que realizan los empresarios (titulares de las marcas), para que marcas similares o casi idénticas, a nombre de titulares diferentes, utilizadas para identificar productos iguales, similares o distintos, puedan coexistir en el mismo territorio para su comercialización o para su registro.”218

218 Ramírez Vallecilla, N.M. y Vernaza Gómez, Pablo Rubén. (2016). La idoneidad de los acuerdos de coexistencia marcaria como medios para evitar el riesgo de confusión en los consumidores. 27. 
Por lo antes expuesto, se puede comprobar que la resolución alterna de conflictos, mediante mecanismos como los Acuerdos de Coexistencia Marcaria, se constituyen como un método que optimiza tanto los costos transaccionales de los procesos, como los resultados alcanzados a través del mismo. Sin embargo, existen múltiples mecanismos de resolución alterna de conflictos mediante los cuales se "(...) busca que el poder de cada una de ellas incida lo menos posible en la resolución del conflicto. En este sistema, lo principal es cuidar la relación de las personas, ya que en la mayoría de los casos, una vez terminado el conflicto, siguen relacionándose o conviviendo en la misma comunidad (...)" ${ }^{219}$. Para resolver de manera alterna estos conflictos, se deben tomar en consideración las siguientes premisas:

“a) Reconocer y aceptar que se vive una situación de conflicto.

b) Tener la voluntad y la disposición para participar en un proceso de resolución del conflicto.

c) Reconocer el Derecho y la legitimidad de ambas partes para plantear sus necesidades e intereses.

d) Estar dispuesto(a) a salvaguardar los intereses fundamentales o integridad de ambas partes.

e) Estar dispuesto(a) a iniciar un intercambio de mutua dependencia, que incluya a los grupos implicados. Su incumplimiento hace que la intervención no proceda." ${ }^{220}$

En tercero y último lugar, existen una serie de principios aplicables a la propiedad intelectual, los cuales pueden ser optimizados mediante la correcta aplicación de la lógica jurídica y la gama de elementos que la conforman. Inicialmente se postula el principio de especialidad y su excepción, el principio de vinculación, los cuales son un reto para los sujetos agentes y principales, puesto a que deben evaluar correctamente la situación actual y determinar la existencia de cualquier

219 González Arreola, A., Vázquez Valencia, L., Archundia Bañuelos , V., Rangel Martínez, G.M. y Castilla Juárez, K. (2011). Servicio Profesional de Derechos Humanos. Mecanismos de resolución alternativa de conflictos (mrac). 31.

220 González Arreola, A., Vázquez Valencia, L., Archundia Bañuelos, V., Rangel Martínez, G.M. y Castilla Juárez, K. (2011). Servicio Profesional de Derechos Humanos. Mecanismos de resolución alternativa de conflictos (mrac). 31. 
tipo de vinculación o competencia que pueda resultar en efectos adversos discutidos previamente. Además, los operadores encargados de impartir justicia en nombre del Estado, deberán evaluar dos o más juicios opositores que pretenden alcanzar objetivos distintos y específicos mediante las distintas técnicas de argumentación.

Las partes involucradas deberán ser capaces de impugnar la argumentación expuesta mediante el uso de cualquiera de las dieciséis técnicas proporcionadas previamente, con el fin de persuadir a la autoridad competente sobre una postura específica. Resulta indispensable tener conocimiento acerca de las falacias, las cuales pueden tornar un proceso dentro de la materia de propiedad intelectual como desfavorable en los casos donde las partes no sean capaces de identificar e impugnar o evadir la técnica de la falacia. Adicionalmente, el lenguaje es uno de los elementos más importantes de la lógica, y aplicable en todos los ámbitos de la vida humana, puesto a que es el medio de comunicación y transmisión de ideas entre individuos, cuyo uso apro-

piado suele favorecer a partes involucradas específicas. Finalmente, se pudo concluir que el uso de métodos como la resolución alterna de conflictos, facilita el cumplimiento de los intereses de las partes involucradas, puesto a que, optimiza tanto los costos transaccionales de los procesos, como los resultados alcanzados a través del mismo, sin la necesidad de acceder a instancias superiores y más costosas.

\section{CONCLUSIONES}

En conclusión, la propiedad intelectual juega un rol sumamente importante en la sociedad actual. Los Estados, alrededor del mundo juntan esfuerzos con el objetivo de promover la importancia de la propiedad industrial, en sus distintos niveles, debido a la amplia gama de beneficios frutos de esta materia de Derecho. Sin embargo, enfrenta una serie de adversidades que deben ser superadas mediante la implementación de medidas que involucren el uso de la lógica. Se puede evidenciar, al igual que la mayoría de sedes administrativas y judiciales estatales, ineficiencia en los procesos y métodos adoptados para alcanzar los fines específicos de las instituciones. La comunicación es un elemento imprescindible para alcanzar cualquier meta, sin embargo, el uso de terminología incomprensible para los individuos ajenos al estudio del Derecho, imposibilita en muchos casos la igualdad de condiciones y consecuentemente se producen graves injusticias. 
En segundo lugar, la propiedad intelectual se encuentra dividida en dos categorías conocidas como la propiedad industrial y los Derechos de autor (por ahora se dejan de lado las obtenciones vegetales como una categoría separada). En sede administrativa, tanto los sujetos agentes como principales, deben ser capaces de emplear las herramientas como el lenguaje, la identificación de falacias, o la argumentación apropiada, con el fin de obtener una decisión favorable y los más justa posible.

En tercero y último lugar, existen una serie de principios aplicables a la propiedad intelectual, los cuales pueden ser optimizados mediante la correcta aplicación de la lógica jurídica y la gama de elementos que la conforman. Inicialmente se postula el principio de especialidad y su excepción, el principio de vinculación, los cuales son un reto para los sujetos agentes y principales, puesto a que deben evaluar correctamente la situación actual y determinar la existencia de cualquier tipo de vinculación o competencia que pueda resultar en efectos adversos discutidos previamente. Asimismo, los operadores encargados de dirimir controversias en nombre del Estado, deberán evaluar dos o más juicios opositores que pretenden alcanzar objetivos diferentes y específicos mediante las distintas técnicas de argumentación. Al existir una realidad que se determine como la correcta, las partes involucradas deberán ser capaces de, tanto en proceso de oposición a registros como en cualquier otra materia del Derecho, impugnar la argumentación expuesta mediante el uso de cualquiera de las dieciséis técnicas proporcionadas previamente, con el fin de persuadir a la autoridad competente sobre una postura específica.

Resulta indispensable tener conocimiento acerca de las falacias, las cuales pueden tornar un proceso dentro de la materia de propiedad intelectual como desfavorable en los casos donde las partes no sean capaces de identificar e impugnar o evadir la técnica de la falacia. Adicionalmente, el lenguaje es uno de los elementos más importantes de la lógica, y aplicable en todos los ámbitos de la vida humana, puesto a que es el medio de comunicación y transmisión de ideas entre individuos, cuyo uso apropiado suele favorecer a partes involucradas específicas.

Finalmente, se puede concluir que el uso de métodos como la resolución alterna de conflictos, facilita el cumplimiento de los intereses de las partes involucradas, puesto a que, optimiza tanto los costos transaccionales de los procesos, como los resultados alcan- 
zados a través del mismo, sin la necesidad de acceder a instancias superiores y más costosas.

\section{REFERENCIAS BIBLIOGRÁFICAS}

Achával, C. (1977). Derecho constitucional, 1ra ed., vol. 1, 2 vols. (Buenos Aires: Depalma)

Aparisi Miralles, A. (1992). Introducción al concepto de Derecho, en Introducción a la Teoría del Derecho, 1ra ed. (Madrid: Tirant lo Blanch)

Arato, J. (2012). Constitutionality and Constitutionalism Beyond the State: Two Perspectives on the Material Constitution of the United Nations. International Journal of Constitutional Law 10 (3):627-59.

Asamblea Nacional del Ecuador. (2009) Código Orgánico de la Función Judicial.

Bidart Campos, G. (1981). Manual de Derecho constitucional argentino (Buenos Aires: Ediar)

Bryce, J. (2015) Constituciones flexibles y Constituciones rígidas, 1ra ed. (Madrid: Centro de Estudios Políticos y Constitucionales)

Cancio Meliá, J. (2002). La Constitución económica: promesas incumplibles. Revista Jurídica Universidad Autónoma de Madrid 0 (7):49101. 92.

Carbonell, M. (1998). Constitución, reforma constitucional y fuentes del Derecho en México, 1ra ed., Serie G: Estudios Doctrinales 197 (Universidad Nacional Autónoma de México: Instituto de Investigaciones Jurídicas, 1998).

Carpizo, J. (1980). La clasificación de las Constituciones. Una propuesta, Boletín Mexicano de Derecho Comparado 1, n. ${ }^{\circ} 38$

Clinton Wheare, K. (1951). Modern Constitutions, vol. 213, Home University Library (Londres: Oxford University Press). 
Contreras, F. (2001). La Idea de Espíritu Del Pueblo, En F.C.V. Savigny, Anales de la Cátedra Francisco Suárez 35

Estupiñán Achury, L. (2011). Federalismos unitarios: Constitución paradigmática y nuevos federalismos, Revista IUSTA 2, n. ${ }^{\circ} 35$

Fernández Bulté, J. (2001). Teoría del Estado y del Derecho. 1ra ed. Vol. 2. Teoría del Derecho. 2 vols. Ciencias Jurídicas. La Habana: Editorial Félix Varela

García Amado, J. (2008). Sobre el neoconstitucionalismo y sus precursores. En Controversias constitucionales, 24-69. Bogotá: Universidad del Rosario.

Guastini, R. (1999). Sobre el concepto de Constitución. Traducido por Miguel Carbonell. Revista Mexicana de Derecho Constitucional 1 (1):161-76.

Hamilton, A. (2015). El Federalista, 1ra ed., Clásicos del pensamiento político (Madrid: Akal Editor)

Herrero de Miñón, M. (1999). La Constitución económica: desde la ambigüedad a la integración. Revista Española de Derecho Constitucional, n. ${ }^{\circ}$ 57:11-32. 12.

Jiménez Campo, J. (1997). Contra la Constitución Material. En Estudios de Derecho Público. Homenaje a Juan José Ruiz Rico, 1:42-54. Madrid: Tecnos.

Kelsen, H. (1979). Teoría Pura del Derecho, trad. Roberto J. Vernengo, 1 ra ed., Estudios Doctrinales 20 (México D.F.: UNAM; Instituto de Investigaciones Jurídicas)

Kohan, N. (1999). Gramsci y Marx. Hegemonía y poder en la teoría marxista, Utopías, nuestra bandera: Revista de debate político, n. ${ }^{\circ} 182$

Lasa López, A. y García Ortiz, A. (2016). Alternativas a la investigación dogmática constitucional tradicional desde el Derecho Europeo. En XIV Jornades de Xarxes d'Investigació en Docència Universitària, 100-116. Alicante: Universidad de Alicante. Instituto de Ciencias de la Educación. 102. 
Lassalle, F. (2012). ¿Qué es una Constitución?, trad. Wenceslao Roces, 1ra ed., Ariel Derecho (Barcelona: Ariel)

Loewenstein, K. (1976). Teoría de la Constitución (Madrid: Ariel)

Lucas Verdú, P. (1976). Curso de Derecho político, 2da ed. (Madrid: Tecnos)

Marcuse, H. y Romero Cuevas, J. (2010). Herbert Marcuse y los orígenes de la teoría crítica. 1ra ed. Clásicos europeos. Madrid: Plaza y Valdés Editores.

Medici, A. (2016). Constitución material y justicia política. Revista Política Latinoamericana 0, n. ${ }^{\circ} 2$ (26 de julio de 2016): 1-20.

Morelli, F. (2007). Entre el antiguo y el nuevo régimen. La historia política hispanoamericana del siglo XIX., Historia Crítica 33

Pérez Royo, J. (2015). La reforma constitucional inviable. 1ra ed. Madrid: Catarata.

Pérez Royo, J. (2007). Curso de Derecho constitucional, 11. ${ }^{\mathrm{a}}$ ed., Manuales Universitarios (Madrid: M. Pons)

Quiroga Lavié, H. (1978). Derecho constitucional, 1ra ed. (Buenos Aires: Depalma)

Sánchez Sánchez, A, (2017). Interpretación constitucional. Eunomía. Revista en Cultura de la Legalidad 0, n. ${ }^{\circ}$ 13: 211-20.

Schmitt, C. (1983). La defensa de la Constitución: estudio acerca de las diversas especies y posibilidades de salvaguardia de la Constitución (Tecnos).

Schmitt, C. (2011). Teoría de la Constitución (Alianza Editorial)

V.I. Lenin, (1976) Obras Completas, 1ra ed., vol. XI, L vols. (Madrid: Akal Editor)

Valencia Mosquera, C (2012). El Estado Social de Derecho colombiano: nativo político de una historia híbrida. Revista Jurídicas 9, n.o 2 
Viciano Pastor, R. y Martínez Dalmau, R. (2011). El nuevo constitucionalismo latinoamericano. Fundamentos para una construcción doctrinal, Revista general de Derecho Público comparado 9.

Wolf-Phillips, L. (1972). Comparative Constitutions | L. Wolf- Phillips | Springer, 1ra ed., Study in Comparative Policy (Palgrave Macmillan UK)

Recibido: 05/08/2017

Aceptado: 28/11/2017

Luis Fernando Samaniego Izurieta: Investigador jurídico de la PUCE.

Mgtr. Guillermo Gonzalo Lascano Báez: Profesor Titular PUCE (Facultad de Jurisprudencia)

Correo electrónico: luisfernando-samaniegoi@gmail.com

Correo electrónico: gglascano@puce.edu.ec 